\title{
Stented Porcine and Pericardial Bioprostheses - A historical review
}

\author{
Andrea De Martino', Giosuè Falcetta' ${ }^{1}$ Aldo D. Milano², Uberto Bortolotti'* \\ 'Cardiovascular Surgery Divisions, University of Pisa, Italy \\ ${ }^{2}$ Department of Cardiac Surgery, University of Bari Aldo Moro, Bari, Italy
}

\section{Article Info}

Article Notes

Received: September 26, 2019

Accepted: October 31, 2019

\section{${ }^{*}$ Correspondence:}

*Prof. Uberto Bortolotti, Division of Cardiac Surgery, University of Pisa Medical School, Pisa, Italy; Telephone No: 338-3759662; Email: uberto48@gmail.com.

C 2019 Bortolotti U. This article is distributed under the terms of the Creative Commons Attribution 4.0 International License.

\section{Abstract}

Stented bioprostheses have been extensively used clinically to replace diseased cardiac valves with the clear advantage over mechanical prostheses of avoiding the use of chronic anticoagulation in most cases. During the past five decades, however, based on clinical and pathological experience, tissue calcification and cusp tears were identified as the main determinants of failure of porcine and pericardial bioprostheses, respectively. Tissue treatments to mitigate dystrophic calcification together with structural modifications in valve design have produced a current generation of bioprosthetic valves which show excellent overall performance and considerably increased durability when compared with old models. Further ongoing research aims to provide even more durable bioprostheses in order to allow reduction of the age threshold for implantation also in younger subjects, helping to contrast effectively the rapidly expanding role of catheter-based interventions.

\section{Introduction}

The history of cardiac prosthetic valves started in 1952 when Hufnagel implanted a ball-valve made of methyl metachrylate, into the descending aorta in a patient with aortic valve disease ${ }^{1}$. Unavailability of cardiopulmonary bypass dictated this unusual application which, however, had almost no benefits for patients with aortic valve disease ${ }^{2}$.

Prosthetic cardiac valve replacement started later when Harken performed the first aortic valve replacement (AVR) in March 1960 with implanting in subcoronary position a caged-ball prosthesis in a patient with aortic stenosis ${ }^{3}$. Albert Starr is credited for the first mitral valve replacement (MVR) with a caged-ball prosthesis performed in $1960^{4}$, but apparently at that time Nina Braunwald had already successfully replaced an incompetent mitral valve using a prosthesis made of polyurethane ${ }^{5}$.

Availability of mechanical prostheses represented a milestone in cardiac surgery, since for patients with either mitral or aortic valve disease the only possible option was represented by closed commissurotomy for mitral stenosis or implantation of rudimentary prostheses into the descending aorta with rather unpredictable results ${ }^{1,6}$. In the ensuing years, however, it was evident that mechanical prostheses were associated with a high risk of thromboembolic and hemorrhagic complications due to lifelong anticoagulation ${ }^{7,8}$. Prosthetic valves made of biological tissues, avoiding anticoagulant treatment, were thus considered the best alternative. Initially, bioprostheses were obtained with segments of fascia lata ${ }^{9}$ or dura mater ${ }^{10}$, but they did not resist to early structural valve deterioration (SVD). 
Binet et al. in $1965^{11}$ were the first to implant a xenograft in aortic position. Inflammatory reaction and cellular ingrowth caused failures of such implants indicating the need for a stent and improved tissue treatment modalities ${ }^{12}$. Glutaraldehyde solutions were extremely effective in eliminating antigenicity and increasing stability of the heterologous tissue, while addition of a stent avoided the risk of cellular ingrowth ${ }^{13,14}$.

The first stented porcine bioprosthesis was implanted 50 years ago in $1969^{15}$, while later stented bioprostheses made of bovine pericardium became available clinically as the most reliable alternative ${ }^{16}$. Both porcine and stented pericardial bioprostheses acquired ever since worldwide acceptance. This review aims to go through the past 5 decades analyzing the various changes in valve designs and tissue preservation dictated by both clinical and pathological evidence leading to the newest generations of bioprostheses witnessing their impact in the clinical scenario of patients with cardiac valve disease.

\section{Stented Porcine Bioprostheses}

Warren Hancock was the first to understand the importance of making readily available to cardiac surgeons a commercially manufactured bioprosthesis of different sizes. This eliminated all potential drawbacks of homemade tissue valves due to the complexity of construction and lack of quality control of such procedure. The first Hancock porcine bioprostheses, fixed in formaldehyde and mounted on a rigid metallic stent, showed high rates of early failures due to SVD while, occasionally, an extended durability of this this $\mathrm{PB}$ model was observed ${ }^{17}$. In the manufacture process of Hancock PBs the rigid metallic stent was then replaced with a polypropylene flexible one to reduce mechanical stresses on commissures and cusps, while glutaraldehyde was introduced in tissue processing, fixation and storage to stabilize collagen cross-links and eliminate antigenicity ${ }^{18}$. This new generation of porcine bioprostheses, the Hancock I, was implanted for the first time in March 1970 in a female patient with mitral valve disease $^{19}$. Subsequently this device was employed with increasing frequency worldwide in mitral, aortic and even tricuspid valve position regardless of patient age and valvular pathology. The initial results were extremely gratifying reporting a low incidence of reoperations for SVD and thromboembolic complications at a mediumterm follow-up further supporting the initial enthusiasm ${ }^{20}$. Subsequently, other companies started to manufacture different models of porcine bioprostheses; some of them were abandoned quite early while others demonstrated good reliability and were implanted until the more recent years $^{21,22}$.

Some early problems encountered with porcine bioprostheses were related to the excessive height of the stent which caused fatal left ventricular outflow tract obstruction and left ventricular rupture when used for $\mathrm{MVR}^{23,24}$. Such complications were eliminated by a lowprofile porcine bioprosthesis which, however, increased the rates of SVD in some models due commissural dehiscences attributed to the peculiar design ${ }^{25}$.

Another drawback of porcine bioprostheses was considered the suboptimal hemodynamic performance particularly when small sizes were used for AVR. The reason was identified in the rigidity of the right coronary cusp of the pig where an evident muscular band is present. To eliminate this problem, the right aortic cusp was replaced by a normal one taken from another porcine aortic valve, thus modifying the prosthetic orifice. This peculiar device had limited acceptance but reported good durability despite a more complex fabrication procedure ${ }^{26}$.

When follow-up increased, approximating the first decade of clinical use, the number of patients requiring reoperation because of SVD also increased. Many explants were therefore available for detailed pathological evaluation which showed various modes of failure. Tissue mineralization, causing bioprosthetic stenosis or incompetence due to cusp rigidity or commissural rupture secondary to dystrophic calcification, was recognized as the major determinant of $S^{27-29}$ (Fig. 1). The limited durability emerged as the most significant disadvantage of porcine bioprostheses because of progressive tissue mineralization which was particularly evident and premature is patients prone to tissue calcification as young patients, those with renal failure and pregnant women ${ }^{30-32}$.

To obtain more durable porcine bioprostheses several modifications were interoduced; 1 ) more flexible materials were used for the stents to avoid creeping ${ }^{33}$; 2) more accurate tissue selection was adopted; 3) zero-pressure fixation was used allowing preservation of cusp corrugation and elasticity ${ }^{34}$; and 4) various anticalcification agents were included in tissue treatment with the aim of minimizing and delaying occurrence of SVD. This has provided new generations of porcine bioprostheses some of these have shown excellent durability after mitral or aortic valve replacement with freedom from SVD $>90 \%$ at 15 and at 20 years respectively ${ }^{35,36}$.

\section{Stented Pericardial Bioprostheses}

The first pericardial xenografts were home-made by Marian Ionescu between 1971 and 1976 ${ }^{37}$. Later, Shiley Laboratories produced the Ionescu-Shiley pericardial BP mounting strips of bovine pericardium on a frame to reproduce the trileaflet anatomy of the human aortic valve; pericardium was fixed in $0.5 \%$ glutaraldehyde buffered to a $\mathrm{pH}$ of 7.4 and the valve then stored in formaldehyde ${ }^{38}$. The first Ionescu-Shiley BP was implanted in 1976 and shortly thereafter also Hancock Laboratories started the 

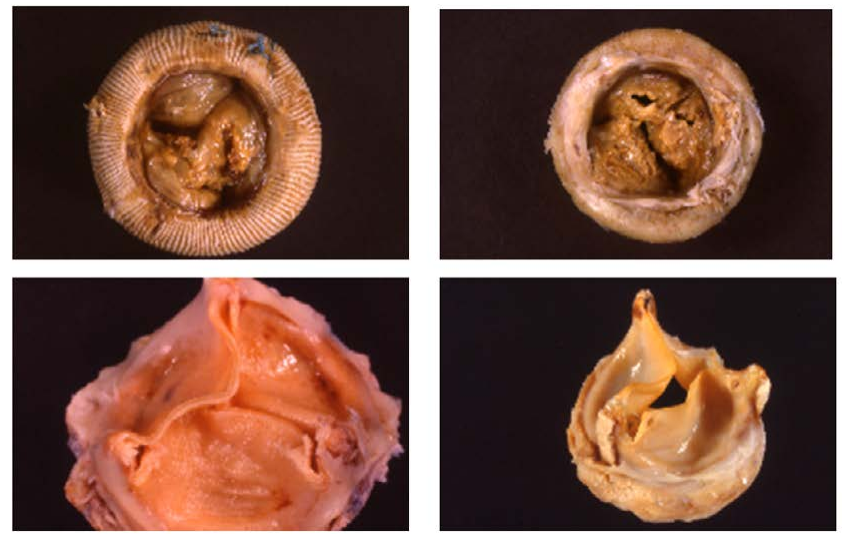

Figure 1: (Upper panel) Porcine bioprostheses explanted because of stenosis due to cusp stiffeness (left) and regurgitation due to cusp tears caused by calcific infiltration (right).

(Lower panel) Pericardial bioprostheses replaced because of regurgitation due to fatigue-induced commissural tears.

production of a similar pericardial xenograft; although early and short-term results were favourable, mechanical failures started to be observed requiring explantation ${ }^{39,40}$; such failures were caused by mechanical stresses on the cusps and commissures and were attributed to an unsound technology (Figure 1). Structural lesions observed in the original models of pericardial bioprostheses were extremely reproducible also in vitro allowing to suggest a classification of such cusp and commissural tears ${ }^{41}$. This was undoubtedly the major drawback of pericardial xenografts since it was soon evident that their hemodynamic performance was clearly superior to that of their porcine counterparts ${ }^{42}$.

Lesson learned from clinical and pathological studies, the latter performed on a considerable number of surgical explants, indicated that modifications in the components of the original models of pericardial bioprostheses were mandatory to eliminate fatigue-induced lesions on the cusps and commissure in order to achieve better long-term durability. This yielded a new generation of pericardial bioprostheses which, by eliminating early mechanical lesions, allowed an increased durability which then became jeopardized by onset of cusp calcification in the long run ${ }^{43}$. However, it has been subsequently demonstrated that avoidance of patient-prosthesis mismatch and the adjunct of anticalcification treatments may increase durability also in pericardial xenografts ${ }^{44}$.

Currently some stented pericardial bioprostheses have successfully responded to the test of time with extended durability over the 15-year limit. Recent reports in fact indicate that in patients $>60$ years of age actuarial freedom from reoperation is approximately $90 \%$ at 15 years after AVR, increasing further in those aged $>70$ years ${ }^{45}$.

\section{Comment}

The last five decades have witnessed great changes in the field of bioprosthetic valves. In the past years considerable clinical and pathological experience has been accumulated. Particularly careful analysis of early and late explants has allowed to identify which were the main determinants of SVD in both porcine and pericardial xenografts. Based on these results the subsequent generations of biological prostheses were manufactured by incorporating modifications particularly in design and tissue treatment. Tissue calcification is a process which takes place whenever a homologous or heterologous tissue is inserted into the heart or bloodstream regardless whether it is fresh or chemically treated; calcification generally depends on the site where the tissue is implanted and by the mechanical stresses it is subjected to while exerting its function ${ }^{46}$. For this reason, the introduction of various antimineralization treatments in bioprosthetic technology has considerably increased durability of both porcine and pericardial valves; among these, the detergent sodium dodecyl sulphate (known as T6) and $\mathrm{p}$-amino-oleic acid have shown to be effective both in experimental animals and in the clinical setting.

It is well known that bioprosthetic durability is influenced by patient age and therefore such devices are still manly indicated in elderly subjects with a limited life expectancy in the belief that they will not outlive their prosthesis and therefore they will not face the risk of reoperation. Furthermore, chronic anticoagulation is often difficult to manage in this subset, where compliance to such treatment may often be poor. It would be important to lower the age threshold for bioprostheses, considered at present to be at 70-75 years, to extend the benefits of avoidance of chronic anticoagulation and related complications also to a younger patient population yet implanting a durable biological valve substitute.

Considering that both porcine and pericardial bioprostheses have often showed an unsatisfactory hemodynamic performance in the small sizes, stentless bioprostheses have been available since many years especially to be used in patients with aortic stenosis and a small aortic annulus. Porcine stentless valves have been almost abandoned while pericardial stentless bioprostheses still represent an important option is specific patient subsets ${ }^{47}$.

Currently research is testing new technologies such as the use of genetically modified pigs or the development of methods of tissue engeneering of cardiac valves to provide even more durable bioprostheses. Furthermore, 3D-printing technology is rapidly developing also in the field of cardiovascular medicine and availability of personalized 3D-printed cardiovascular prostheses may represent a not too far future reality ${ }^{48}$. 


\section{Conclusions}

Stented porcine and pericardial bioprostheses still play a very important role in the management of patients with cardiac valve disease. Trancatheter prosthetic valve implantation has rapidly evolved from an experimental and compassionate treatment to an established procedure also in low-risk patients with results paralleling those of traditional surgical valve replacement. Demonstration that bioprosthetic durability can be further extended may allow to considerably decrease the age limit for such devices helping to balance the role of catheter-based interventions which might therefore be reserved at an older age as valvein-valve procedures in case of bioprosthetic failure.

\section{References}

1. Hufnagel CA, Harvey WP. The surgical correction of aortic regurgitation. Preliminary report. Bull Georgetown Univ Med Center. 1954; 6: 60-1.

2. Gott VL, Alejo DE, Cameron D. Mechanical heart valves: 50 years of evolution. Ann Thorac Surg. 2003; 76: S2230-9.

3. Harken DE, Soroff HS, Taylor WJ, et al. Partial and complete prostheses in aortic insufficiency. J Thorac Cardiovasc Surg. 1960; 40: 744-62.

4. Starr A, Edwards ML. Mitral replacement: clinical experience with a ball-valve prosthesis. Ann Surg. 1061; 154: 726-40.

5. Braunwald NS, Cooper TC, Morrow AG. Complete replacement of the mitral valve. J Thorac Cardiovasc Surg. 1960; 40: 1-11.

6. Hanlon CR, Kaiser GC, Mudd JG, et al. Closed mitral commissurotomy for mitral stenosis. Ann Surg. 1968; 167: 796-800.

7. Murphy DA, Levine FH, Buckley MJ, et al. Mechanical valves: a comparatoive analysis of the Starr-Edwards and Björk-Shiley prostheses. J Thorac Cradiovasc Surg. 1983; 86: 746-52.

8. Edmunds LH jr. Thombotic and bleeding complications of prosthetic heart valves. Ann Thorac Surg. 1987; 44: 430-45.

9. Senning A, Rothlin M. Reconstruction of the aortic valve with fascia lata. Initial and long-term results. Vasc Surg. 1973; 7: 29-35.

10. Zerbini EJ. Results of replacement of cardiac valves by homologous dura mater valves. Chest. 1975; 67: 706-10.

11. Binet JP, Duran CG, Carpentier A, et al. Heterologous aortic valve transplantation. Lancet. 1965; 2:1275.

12. Carpentier A. From valvular xenograft to valvular bioprosthesis: 1965-1970. Ann Thorac Surg. 1989; 48: S73-4.

13. Carpentier A, Lemaigre G, Robert L, et al. Biological factors affecting long-term results of valvular heterografts. J Thorac Cardiovasc Surg. 1969; 58: 467-83.

14. Carpentier A, Deloche A, Relland J, et al. Six-year follow-up of glutaraldehyde-preserved heterografts. With particular reference to the treatment of congenital valve malformations. J Thorac Cradiovasc Surg. 1974; 68: 771-81.

15. Hancock WD. Valvular xenograft to bioprosthesis. Ann Thorac Surg. 1990; 49: 166-70.

16. Ionescu MI, Pakrashi BC, Holden MP, et al. Results of aortic valve replacement with frame-supported fascia lata and pericardial grafts. J Thorac Cardiovasc Surg. 1972; 64; 340-53.

17. Bortolotti U, Milano A, Mazzucco A, et al. Longevity of the formaldehyde-presetrved Hancock porcine heterograft. J Thorac Cardiovasc Surg. 1982; 84: 451-3.
18. Bortolotti U, Milano A, Valente $\mathrm{M}$, et al. The stented porcine bioprosthesis. A 50-year journey through hopes and realities. Ann Thorac Surg. 2019; 1908: 304-8.

19. Gallucci V, Bortolotti U, Milano A, et al. Isolated mitral valve replacement with the Hancock bioprosthesis: a 13-year appraisal. Ann Thorac Surg. 84; 38: 571-8.

20. Cèvese PG, Gallucci V, Morea M, et al. Heart valve replacement with the Hancock bioprosthesis. Analysis of long.-term results. Circulation. 1977; 56: II-111-6.

21. Angell WW, Angell JD, Sywak A. The Angell-Shiley porcine xenograft. Ann Thorac Surg. 1979; 28: 537-53.

22. Jamieson WR, Hayden RI, Miyagishima RT, et al. The CarpentierEdwards standard porcine bioprosthesis: clinical performance to 15 years. J Card Surg. 1991; 6 (Suppl): 550-6.

23. Bortolotti U, Thiene G, Casarotto D, et al. Left ventricular rupture following mitral valve replacement with a Hancock bioprosthesis. Chest. 1980; 77: 235-7.

24. Thiene G, Bortolotti U, Casarotto D, et al. Prosthesis left-ventricle disproportion in mitral valve replacement with the Hancock bioprosthesis: pathologic observations. In 'Bioprosthetic Cardiac Valves', Sebening F, Klovekorn WP, Meisner H, Struck E Eds, Eberl GmbH, Immenstadt/Allgau. 1979: 357-65.

25. Bortolotti U, Milano A, Mazzucco A, et al. Influence of prosthetic design on durability of the Liotta porcine valve in the mitral position. Ann Thorac Surg. 1990; 50: 734-8.

26. Cohn LH, Di Sesa V, Collins JJ Jr. The Hancock modified-orifice porcine bioprosthetic valve: 1976-1988. Ann Thorac Surg. 1989; 48 (3 Suppl): S81-2.

27. Milano A, Bortolotti U, Talenti E, et al. Calcific degeneration as the main cause of porcine bioprosthetic valve failure. Am J Cardiol. 1984; 53: 1066-70.

28. Bortolotti U, Milano A, Thiene G, et al. Original expectations of the Hancock valve and 20 years of clinical reality. Eur J Cardio-thorac Surg. 1992; 6 (Suppl. 1): S75-8.

29. Valente M, Bortolotti U, Thiene G. Ultrastructural substrates of dystrophic calcification in porcine bioprosthetic valve failure. Am J Pathol. 1985; 119: 12-21.

30. Thandroyen FT, Whitton IN, Pirie D, et al. Severe calcification of glutaraldehyde-preserved porcine xenografts in children. Am J Cardiol. 1980; 45: 690-6.

31. Kuzela DC, Huffer WE, Coinger JD, et al. Soft tissue calcification in chronic dialysis patients. Am J Pathol. 1977; 86: 403-24.

32. Bortolotti U, Milano A, Mazzucco A, et al. Pregnancy in patients with a porcine bioprosthesis. Am J Cardiol. 1982; 50: 1051-4.

33. Valente M, Bortolotti $\mathrm{U}$, Thiene $\mathrm{G}$, et al. Post bending of the polypropylene flexible stent in mitral Hancock bioprostheses. Eur J Cardio-thorac Surg. 1987; 1: 134-8.

34. Veseli I. Analysis of the Medtronic Intact bioprosthetic valve. Effects of "zero pressure" fixation. J Thorac Cardiovasc Surg. 1991; 101: 90-9.

35. Celiento M, Blasi S, De Martino A, et al. The Mosaic mitral valve bioprosthesis: A long-term clinical and hemodynamic follow-up. Texas Heart Inst J. 2016; 43: 13-9.

36. Celiento M, Ravenni G, Tomei L, et al. Excellent durability of the Mosaic aortic bioprosthesis at extended follow-up. J Heart Valve Dis. 2018; 27: 97-103.

37. Ionescu MI, Pakrashi BC, Holden MP, et al. Results of aortic valve replacement with frame-supported fascia lata and pericardial grafts. J Thorac Cardiovasc Surg. 1972; 64: 340-53.

38. Ionescu MI, Tandon AP, Mary DAS, et al. Heart valve replacement with 
the Ionescu-Shiley pericardial xenograft. J Thorac Cardiovasc Surg 1977; 73: 31-42.

39. Bortolotti U, Milano A, Mazzucco A, et al. The Hancock pericardial xenograft: incidence of early mechanical failures at a medium-term follow-up. Eur J Cardio-thorac Surg. 1988; 2: 458-64.

40. Thiene G, Bortolotti $U$, Valente $M$, et al. Mode of failure of the Hancock pericardial xenograft. Am J Cardiol. 1989; 63: 129-33.

41. Gabbay S, Bortolotti U, Wasserman F, et al. Fatigue-induced failure of the Ionescu-Shiley pericardial xenograft in the mitral position. In vivo and in vitro correlation and a proposed classification. J Thorac Cardiovasc Surg. 1984; 87: 836-44.

42. Milano AD, Blanzola C, Mecozzi G, et al. Hemodynamic performance of stented and stentless aortic bioprostheses. Ann Thorac Surg. 2001; 72: 33-8.

43. Kaneko T, Gosev I, Leacche M, et al. Early structural valve deterioration of the Mitroflow aortic bioprosthesis. Circulation. 214; 130: 1997-8.
44. Blasi S, Ravenni G, Celiento M, et al. Durability of the Mitroflow pericardial prosthesis: influence of patient-prosthesis mismatch and new anticalcification treatment. Thorac Cardiovasc Surg. 2019; doi: 10.1055/s-0038-1667201.

45. Forcillo J, Pellerin M, Perrault LP, et al. Carpentier-Edwards pericardial valve in the aortic position: 25-year experience. Ann Thorac Surg. 2013; 96: 486-93.

46. Gabbay S, Bortolotti U, Factor S, et al. Calcification of implanted xenograft pericardium. Influence of site and function. J Thorac Cardiovasc Surg. 1984; 87: 782-7.

47. Thalmann M, Grubitzsch H, Matschke K, et al. A European multicenter study of 616 patients receiving the Freedom Solo stentless bioprosthesis. Ann Thorac Surg. 2016; 101: 100-8.

48. Vukicevic M, Mosadegh B, Min JK, et al. Cardiac 3D printing and its future directions. JACC Cardiovasc Imag. 2017; 2: 171-184. 
